\title{
Infrared Spectroscopy Applied to Materials Used as Thermal Insulation and Coatings
}

\author{
Natália Beck Sanches, Ricardo Pedro, Milton Faria Diniz², Elizabeth da Costa Mattos², \\ Silvana Navarro Cassu², Rita de Cássia Lazzarini Dutra²
}

\begin{abstract}
It is very important to control the characteristics of a polymer used in rubber compositions and paints in aerospace applications. Hence, the development of simple and fast methodologies that allow the identification of these compositions becomes attractive to researches carried out in this area. This study has evaluated infrared (IR) techniques, such as transmission, universal attenuated total reflection (UATR), and attenuated total reflection (ATR), for the characterization of elastomers and paints. It takes into consideration the characteristics of surface techniques, such as the depth of penetration of the IR beam into the sample. The presence of additives in low concentrations on paints was only detected by UATR after grinding the components. Results show that it is possible to differentiate rubber mixtures with similar IR spectra and to detect small amounts of additives in the surface of coatings.
\end{abstract}

KEYWORDS: Rubbers, paints, infrared, FT-IR, ATR, UATR.

\section{INTRODUCTION}

Polymers are used in many industrial areas, such as the aerospace (Dutra et al., 2002; Oliveira et al., 2011). Their different types, with specific characteristics, are used in propellant (Sciamareli et al., 2012), composites, rubbers (Ferrari et al., 2012; Santos et al., 2013), and coatings (Blackford, 1999).

The resin most often utilized in aerospace applications is hydroxyl terminated polybutadiene (HTPB), which is used in propellants and flexible insulation protection (Lourenço et al., 2006; Crespim et al., 2007). It is known that phenolic resins are employed in composites for rigid thermal insulation, while epoxy are used in adhesive compositions for these same protections and in polymer arrays for the aeronautical sector (Pardini, 2000). Rubbers are used in flexible thermal insulation, and the most cited ones in literature for using in aerospace applications are copolymers of acrylonitrile and butadiene (NBR) and ethylene-propylene-diene rubber (EPDM) (Moraes et al., 2007).

Traditionally, aircraft paints are coatings with specific characteristics and requirements, because in extreme cases the use of a defective one may contribute to injuries in a catastrophic scale (Blackford, 1999). The requirements are associated with the environment in which modern aircrafts are used and how they are painted, among other factors. Thus, there are significant differences in formulations used for the aerospace sector compared to other industrial areas, allowing the use of products that can cause damage to people's health, such as chromate pigments, or to the environment, like large amounts of solvents.

1. Instituto Tecnológico de Aeronáutica - São José dos Campos/SP - Brazil 2.Instituto de Aeronáutica e Espaço - São José dos Campos/SP - Brazil Author for correspondence: Rita de Cássia Lazzarini Dutra | Praça Marechal Eduardo Gomes, 50 - Vila das Acácias | CEP 12.228-904 São José dos Campos/SP Brazil | Email: ritarcld@iae.cta.br

Received: 11/07/13 | Accepted: 18/10/13 
Generally, solvents are used to decrease viscosity and facilitate the application of paints. The vehicle or binder is the chemical component that will generate a film on the surface, besides being responsible for keeping the other constituents scattered and clumped. Fillers are materials that provide specific properties to paints, for example, the magnetic nanoparticles that turn aircrafts non-detectable to radars. The additives are compounds used from storage to product application. For example, microbicides preserve the paint during its storage and catalysts reduce the time of film formation during product application (Mello et al., 2012).

With regard to the analysis of polymers used in the aerospace industry, there are studies in the literature (Sanches et al., 2006; ASTM D3677-10, 2010; Romão et al., 2006; Hori et al., 1990) that employ mid infrared (MIR) spectroscopy for identification, characterization, and quantification of materials. In these investigations, analyses of materials using Fourier transform infrared (FT-IR) techniques with variation of the parameters, in different layers of the surface, were not explored.

It is also known that some components present in paints cannot be directly analyzed by using conventional FT-IR techniques, because the characteristic bands overlap with absorptions of other components often seen in high concentrations. Although the study of bands overlapping could be done by using mathematical methods, such as derivatives and deconvolution to quantify components, these ones, in some cases, are complex and depend on the thickness of the analyzed samples. This limitation becomes even more relevant when additives are present in extremely low concentrations. A specific methodology must then be studied.

The FT-IR literature emphasizes that, in the analysis of multiple components systems, there are factors to be considered: influence of sample preparation, total or partial analyses of composition (Allen, 1992; Dutra et al., 1995), and the technique used to obtain the spectrum, single or coupled (Mattos et al., 2004; Almeida et al., 2002; Mateo et al., 2009). In these cases, it is helpful to perform the evaluation of characteristic functional groups, the query to the database of reference spectra (Smith, 1979) using spectra software (Szafarska et al., 2009), and the interpretation of similar studies to highlight the limitations and potential of techniques (Miliani et al., 2002).
Different FT-IR techniques may be suitable for the study of many kinds of materials, according to their characteristics. The most common surface technique is the attenuated total reflection (ATR), which can be used for the analysis of liquid and dried paint films (Mazzeo et al., 2007; Zhang et al., 2009). In the ATR spectroscopy, the radiation passing through the crystal reflects totally on its internal surface (Waltham, 2005). When a radiation absorbing material is placed in contact with a crystal, the infrared (IR) beam penetrates the thin layer of the sample surface and loses energy, causing the attenuated total reflectance. In this technique, good contact between the sample and the crystal is essential (Pandey and Kulshreshtha, 1993).

The penetration depth of the IR beam into the sample depends on the IR radiation angle of incidence, the radiation wavelength, and the refractive indices of the crystal and sample. Ge crystals are able to analyze thinner surfaces (Pandey and Kulshreshtha, 1993). In the ATR technique, different species of the sample surface and interior can be revealed depending on the analysis procedure. The literature reports (Pandey and Kulshreshtha, 1993; PerkinElmer, 2005) and experiences indicate that this aspect must be considered if the study requires selective analysis of the very superficial layer.

Ultimate FT-IR techniques, such as the universal ATR (UATR), have found prominence in the analysis of different materials (PerkinElmer, 2005; Abidi and Hequet, 2005). This technique of internal reflection is able to perform nondestructive analysis of solids, powders, liquids, and gels. In it, the IR beam passes through an ATR element composed of $\mathrm{ZnSe}$ (refractive index 2.67) or diamond-KRS-5 (refractive index 2.42), with high refractive index, and reaches the surface of the sample.

One of the prerequisites of the UATR technique is good contact between the crystal and the sample surface. The probe strength can be adjusted to obtain the most suitable contact, since different pressure levels influence directly on the intensities of the obtained spectra. Because the IR beam does not penetrate deeply into the sample, this technique is suitable for analyzing surfaces with thickness of only a few microns (Pandey and Kulshreshtha, 1993).

It was observed in the literature some gaps related to the use of surface FT-IR techniques, varying the degree of sampling depth. Hence, it was concluded that it is essential the development of new characterization methodologies that 
enable rapid identification of the different materials used in the aerospace industry. The aim of this work was to show the new results obtained by the Chemical Department of the Instituto de Aeronáutica e Espaço (AQI/IAE), in the characterization of different types of materials by using FT-IR reflection techniques, such as ATR and UATR. In addition, the transmission FT-IR technique was applied to identify rubber mixtures.

\section{EXPERIMENTAL}

The nitrile rubber (NBR) and rubber mixtures used in this study were prepared in AQI/IAE. The paint and additives were provided by Rohm and Haas. The chemical structure of the additives carbendazim (2-methoxycarbonylamino-benzimidazole), Diuron ( $\mathrm{N}^{\prime}$-(3,4-dichlorophenyl)-N, N-dimethylurea)) and OIT (2-N-octyl-4-isothiazolin-3-one) is shown in the text. Portions of the samples, before and after extraction with acetone, were also subjected to Beilstein and acidresistance tests (Dutra and Diniz, 1993). A treatment with heated ortho-dichlorobenzene was performed as well.

\section{EVALUATION OF TRANSMISSION AND REFLECTION FT-IR TECHNIQUES FOR CHARACTERIZATION OF RUBBERS}

NBR was analyzed qualitatively by transmission, preparing the sample by pyrolysis (Smith, 1979) after extraction in methanol for eight hours, using the liquid film technique. For the UATR analysis, the NBR sample was placed in contact with the surface of the crystal and a force of $80 \mathrm{~N}$ was applied with the aid of an articulated arm. For ATR (KRS-5 or Ge) analysis, the NBR sample was placed on both sides of the crystal. In this study, KRS-5 (TlBr-crystal mixture TlI) with refractive index 2.4 and Ge with refractive index 4.0 crystals were utilized. The filler was analyzed by transmission, preparing the specimen with the $\mathrm{KBr}$ disc technique.

\section{EVALUATION OF TRANSMISSION FT-IR TECHNIQUES FOR CHARACTERIZATION OF RUBBERS AND THEIR MIXTURES}

An unknown mixture of rubbers was analyzed qualitatively by transmission, preparing the sample by pyrolysis after extraction for eight hours in acetone, using the liquid film technique (Smith, 1979). All analysis were performed using the spectrometer Spectrum One PerkinElmer (resolution $4 \mathrm{~cm}^{-1}$, gain 1, spectral range 4000$400 \mathrm{~cm}^{-1}, 40$ scans).

\section{UATR ANALYSIS OF PAINTED SURFACE}

A paint film was applied on a flat glass substrate. After drying, the film was removed by scraping and then analyzed. The paints additives were analyzed directly, without the need of sample preparation. UATR analysis was performed using the spectrometer Spectrum One, PerkinElmer, DTGS detector (resolution $4 \mathrm{~cm}^{-1}$, spectral range $4000-550 \mathrm{~cm}^{-1}$, gain 1, 20 scans). Spectra were obtained using the accessory UATR and applying a force of $80 \mathrm{~N}$.

\section{RESULTS AND DISCUSSION}

This section presents the evaluation of FT-IR techniques for the analysis of elastomers and paints, using methods traditionally applied and developed in AQI/IAE laboratories.

\section{APPLICABILITY OF TRANSMISSION AND REFLECTION FT-IR TECHNIQUES FOR CHARACTERIZATION OF RUBBERS}

It is known that conventional FT-IR techniques can be applied to the characterization of rubbers (Matheson et al., 1994; Wake et al., 1983; Williams and Besler, 1995). In this work, different information is obtained by using independently transmission (liquid phase of pyrolyzate) and reflection (ATR and UATR) techniques. These were used for the characterization of the polymer and the filler, respectively.

Figure 1 shows the FT-IR spectra obtained from NBR analysis by using different techniques. It is observed that the analysis of the liquid phase of the pyrolyzate resulted in a spectrum (Fig. 1a) with the base polymer characteristic absorptions. The band observed at $2237 \mathrm{~cm}^{-1}$ is assigned to the stretching of the $\mathrm{C}-\mathrm{N}$ group, and the peaks in the region of $1000-900 \mathrm{~cm}^{-1}$ are assigned to the wagging bending vibration of vinyl and trans $\mathrm{C}=\mathrm{C}$ groups. In the spectra obtained by reflection using different crystals (Figs. 1b, 1c and 1d), the band at $2237 \mathrm{~cm}^{-1}$ showed lower intensity and there was a contribution of $\mathrm{Si}-\mathrm{O}$ groups in the region of $1100-900 \mathrm{~cm}^{-1}$, 
the latter related to the load used in the formulation (Smith, 1979). Figure 1e shows these load-related bands, analyzed by transmission ( $\mathrm{KBr}$ pellet), after rubber calcination.

Although the spectra obtained by using reflection techniques did not clearly evidence the absorptions of NBR, they were able to indicate the filler used in the formulation. In order to obtain the same filler related information by using transmission techniques, it is necessary to apply supplementary sample preparation techniques, such as $\mathrm{KBr}$ pellet after rubber calcination.

The use of reflection techniques can also be applied to the detection of silica filler in silicone rubbers, instead of using a large number of techniques to achieve the same goal. This is important because applying some sample preparation techniques for transmission analysis, such as calcination, can induce the formation of silicon oxide in this type of rubber.

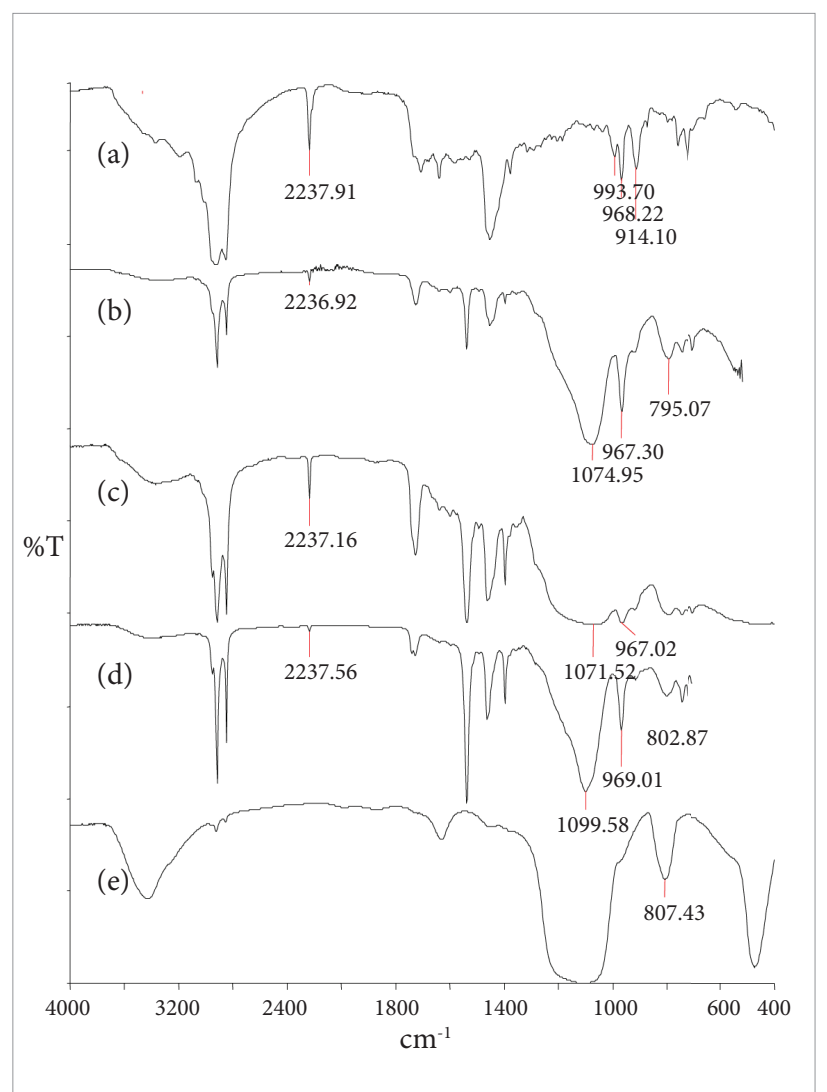

Figure 1. FT-IR spectra obtained from analysis of the nitrile rubber through different techniques: (a) Nitrile rubber transmission pyrolyzed (liquid film), (b) Nitrile rubber - UATR, force 80, (c) Nitrile rubber - ATR/KRS-5, (d) Nitrile rubber $\mathrm{ATR} / \mathrm{Ge}$, and (e) residue obtained after calcination of rubber on Bunsen burner - transmission, $\mathrm{KBr}$ pellet.
It might lead to misinterpretation, since not all silicone rubbers have silica as filler.

\section{APPLICABILITY OF FT-IR TRANSMISSION TECHNIQUES FOR THE CHARACTERIZATION OF RUBBERS AND THEIR MIXTURES}

As it is known, pyrolysis of rubbers without solvent extraction is performed only to determine the base polymer and the best solvent for its extraction. Because additives bands are also observed, it is necessary to extract the rubber sample in order to obtain a spectrum that shows only characteristic bands of the polymer (Smith, 1979; Wake et al., 1983). The identification of rubber mixtures by using FT-IR is possible, providing that their characteristic bands are different, without the occurrence of overlapping.

Figure 2 illustrates the application of the FT-IR transmission technique (pyrolysis without control of temperature) to an unknown mixture of rubbers, with and without extraction.

The main absorptions observed in the spectrum of the pyrolyzed rubber without extraction (Fig. 2a) and their attributions (Smith, 1979) are: $1376 \mathrm{~cm}^{-1}$, angular bending vibration $(\delta)$ of $\mathrm{CH}_{3}$ groups; 991 and $909 \mathrm{~cm}^{-1}$, wagging bending vibration $(\omega)$ of vinyl group; $964 \mathrm{~cm}^{-1}$, wagging bending vibration of trans groups; and $887 \mathrm{~cm}^{-1}$, wagging bending vibration of vinylidene groups. These absorptions positions, shapes, and intensities suggest the presence of EPDM and/or NR (poly cis-isoprene or natural rubber) elastomers, which requires the use of acetone solvent for removal of the plasticizer and other additives (Wake et al., 1983).

The sample was extracted for eight hours in Soxhlet apparatus, using acetone as the solvent. Then, it was pyrolyzed and analyzed as a liquid film (Fig. 2b). The same main bands were observed, as expected, because plasticizers used in EPDM and NR formulations are apolar and their groups do not contribute with different absorptions in the spectrum of the pyrolyzates without extraction. The band at $887 \mathrm{~cm}^{-1}$ is characteristic of NR rubber, but it is also present in the EPDM rubber. To further elucidate the chemical structure of the sample, a comparison was made between the IR spectrum of this sample and that of known EPDM and NR rubbers, pyrolyzed after extraction in acetone (Figs. $2 \mathrm{~b}$ and $2 \mathrm{c}$ ). 


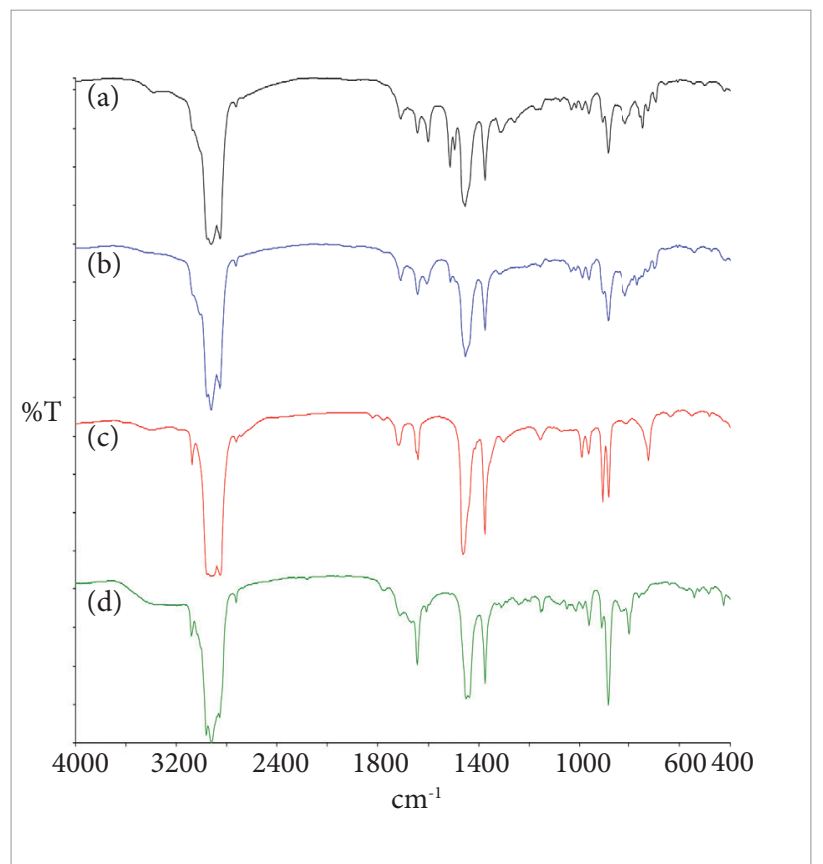

Figure 2. FT-IR spectra of (a) sample pyrolyzed without extraction, (b) sample pyrolyzate after extraction with acetone, (c) spectrum of known EPDM, pyrolyzed after extraction with acetone, and (d) spectrum of known NR, pyrolyzed after extraction with acetone.

To better identify the EPDM bands, it was also applied a treatment with hot ortho-dichlorobenzene to the sample, which was then pyrolyzed to obtain the IR spectrum. The resultant IR spectrum (Fig. 3a) showed more clearly the presence of EPDM rubber (bands marked with an asterisk), as can be visualized in Fig. $3 \mathrm{~b}$.

The Beilstein test was performed before and after extraction in acetone to confirm the absence of halogen compounds, expected because EPDM and NR do not present halogens in their compositions. The negative result corroborates the hypothesis of the presence of these elastomers.

The acid-resistance test, which basically classifies the rubber resistance when treated with an acid mixture at $40^{\circ} \mathrm{C}$ and $70^{\circ} \mathrm{C}$, was also performed in the sample to elucidate the mixture composition. The sample did not show degradation at $40^{\circ} \mathrm{C}$ in the time established for the test, i.e. 15 minutes (Dutra and Diniz, 1993). At $70^{\circ} \mathrm{C}$, it was observed degradation in around three minutes, confirming that the rubber has a certain content of EPDM. If the sample contained only NR, it would resist for only a few seconds, for less than one minute.

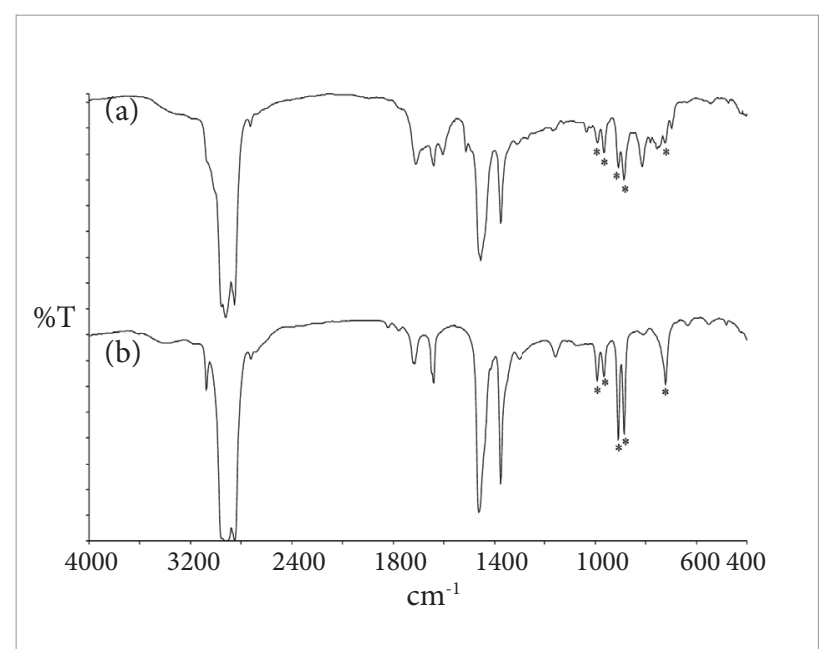

Figure 3. FT-IR spectra of (a) pyrolyzed insoluble portion, after ortho dichloro benzene treatment (previously extracted in acetone for eight hours), and (b) pyrolysed EPDM (reference).

Basically, FT-IR analysis of the liquid pyrolysis products, associated with Beilstein and acid resistance tests (Dutra and Diniz, 1993), within the detection limits of the FT-IR technique, indicated that the unknown rubber consists of NR and EPDM.

The utilization of acid-resistance test to characterize rubber mixtures (Dutra and Diniz, 1993), also developed in IAE/AQI, is important especially in EPDM mixtures. This elastomer is considered as a replacement for NBR in the aerospace industry. The addition of NR in a rubber mixture may be intended to lower the cost, but it certainly affects properties. Hence, we can conclude that appropriate methodologies for the quality control of materials, contemplating the application of different tests and analyses, are fundamental to achieve the outlined goals, essentially in the aerospace industry, where materials require specific properties.

\section{APPLICABILITY OF TRANSMISSION AND REFLECTION FT-IR TECHNIQUES FOR CHARACTERIZATION OF PAINTS}

As mentioned, aeronautical coatings may contain hazardous products, such as chromate pigments (Blackford, 1999). The identification of chromate anions $\left(\mathrm{CrO}_{4}^{2-}\right)$ can be performed by IR spectroscopy in the region of 800 to $900 \mathrm{~cm}^{-1}$ (Smith, 1979).

Copper chromite is used in the aerospace industry as a catalyst precursor (Faillace et al., 1999). It was characterized by transmission $(\mathrm{KBr}$ disc), reflection, and 
photoacoustic detection (PAS) FT-IR techniques in an article published by the IAE/AQI group (Campos et al., 2003). It was observed that FT-IR techniques are able to indicate the catalyst method of synthesis. This is possible by using surface analysis techniques, with different degrees of sampling depth, without the need for other characterization methods. Therefore, the techniques used in this study (Campos et al., 2003) have emerged as new alternatives for characterizing other types of catalysts or materials containing these kinds of compounds, such as chromium-based anions.

Certain additives, as OIT, diuron, and carbendazim, are added in small contents to preserve coatings during storage (Mello and Suarez, 2012). In this study, the methodology of chromium-based compounds (Campos et al., 2003) was applied to the analysis of paints, with different degrees of sampling depth.

\section{ANALYSIS OF PAINTS BY UATR}

Figure 4 shows the UATR spectra of additives OIT, carbendazim, and diuron, painted with and without preservatives, dried resin, and filler.

The main bands observed in the FT-IR spectrum of OIT (Fig. 4a) are: 2924, 2855 and $722 \mathrm{~cm}^{-1}$ (stretching and rocking bending vibration of the $\mathrm{CH}_{2}$ aliphatic group), $1618 \mathrm{~cm}^{-1}$ (stretching of the $\mathrm{C}=\mathrm{O}$ group), as well as at 1263 and $781 \mathrm{~cm}^{-1}$ (vibration of five-membered heterocyclic ring). The spectrum of carbendazim (Fig. 4b) showed bands at: $3320 \mathrm{~cm}^{-1}$ (stretching of $\mathrm{N}-\mathrm{H}$ secondary group), $1710 \mathrm{~cm}^{-1}$ (stretching of $\mathrm{C}=\mathrm{O}$ group), $1627 \mathrm{~cm}^{-1}$ (stretching of the $\mathrm{C}=\mathrm{O}$ group and of the $\mathrm{C}=\mathrm{N} 5$-membered heterocyclic ring), $1591 \mathrm{~cm}^{-1}$ (stretching of the $\mathrm{C}-\mathrm{C}$ aromatic and $\mathrm{C}=\mathrm{N}$ groups), 1266 and $1093 \mathrm{~cm}^{-1}$ (stretching of the $\mathrm{C}-\mathrm{O}$ group), and $726 \mathrm{~cm}^{-1}$ (vibration of five-membered heterocyclic ring and of the $\mathrm{C}-\mathrm{H}$ aromatic substitution group).

The spectrum of the additive Diuron (Fig. 4c) shows bands at: $3280 \mathrm{~cm}^{-1}$ (stretching of the $\mathrm{N}-\mathrm{H}$ group), $1651 \mathrm{~cm}^{-1}$ (stretching of $\mathrm{C}=\mathrm{O}$ and $\mathrm{C}=\mathrm{N}$ groups), $1584 \mathrm{~cm}^{-1}$ (stretching of the C-C aromatic group), 1473, 1298 and $1186 \mathrm{~cm}^{-1}$ (stretching of the $\mathrm{C}-\mathrm{N}$ group), $1132 \mathrm{~cm}^{-1}$ (wagging of $\mathrm{C}-\mathrm{Cl}$ aromatic group), as well as 864 and $813 \mathrm{~cm}^{-1}$ (bending vibration of the $\mathrm{CH}$-tri-aromatic substitution group) (Smith, 1979; Silverstein et al., 2005.

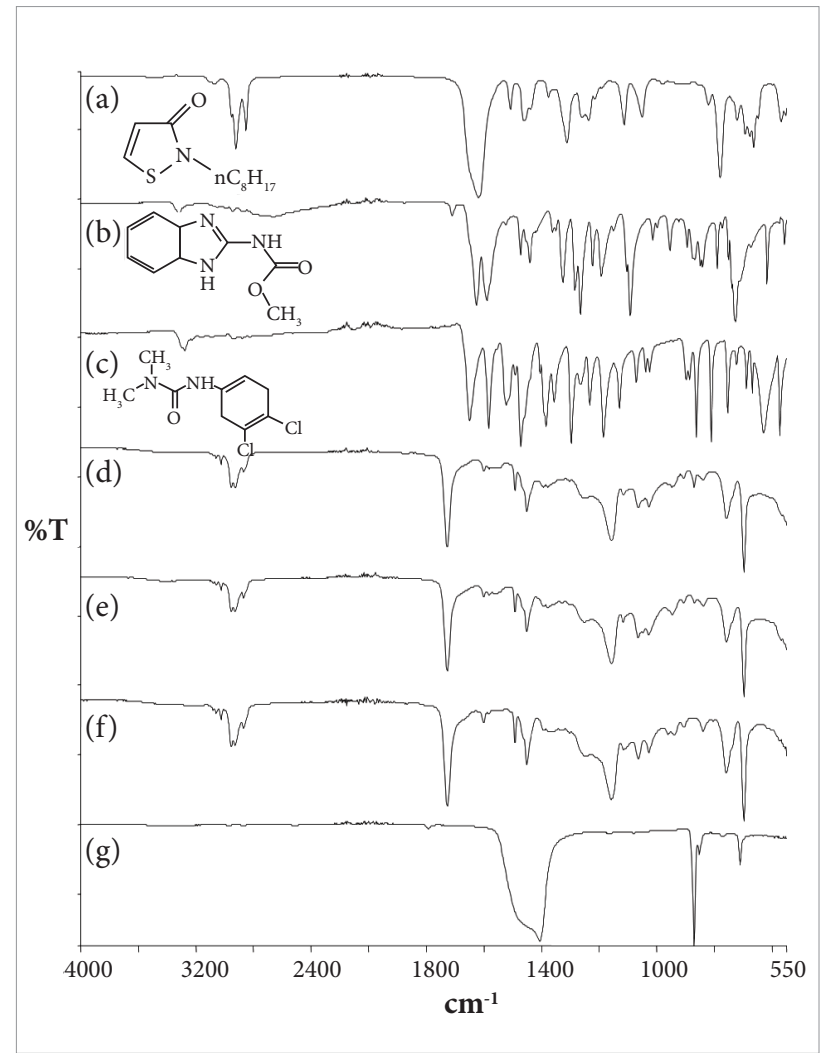

Figure 4. UATR spectra of: (a) OIT, (b) carbendazim, (c) diuron, (d) paint without preservatives, (e) paint with preservatives, (f) dry resin, and (g) calcium carbonate.

The additives OIT, carbendazim and diuron presented intense peaks that could be potentially used as analytical bands. However, the direct analysis of these compounds in the paint, by using UATR, was not possible because spectra of the paint, without (Fig. 4d) and with (Fig. 4e) preservatives are virtually identical. The resin (Fig. 4f) and filler (Fig. 4g) are present in high concentrations, so these ingredients could be the major interferences to the direct analysis. In fact, the main bands observed are associated with the resin (Fig. 4f): $1728 \mathrm{~cm}^{-1}$ (stretching of the $\mathrm{C}=\mathrm{O}$ group), $1159 \mathrm{~cm}^{-1}$ (stretching of the $\mathrm{C}-\mathrm{O}$ group), and $698 \mathrm{~cm}^{-1}$ (bending vibration of $\mathrm{C}-\mathrm{H}$ aromatic substitution group).

Although the characterization of preservatives in the surface of paints by UATR was not possible in the studied conditions, it is known that they are added to the compound to control proliferation of microorganisms (Lindner, 2005). Thus, we can suppose that some content of preservatives is present on the film surface. 
It is known that the diffusion phenomenon is a process that depends on the size of the involved particles. The rate of diffusion is inversely proportional to the size of the particle. Hence, a smaller particle will diffuse faster and migrate easier to the surface. Preservatives were grinded to obtain different particle sizes. These samples were studied to investigate the effect of particle size on surface analysis results.

\section{EVALUATION OF THE INFLUENCE OF PARTICLE SIZE IN THE DETECTION OF PRESERVATIVES AT THE PAINTED SURFACE BY UATR}

Results of grinded preservatives are presented in Table 1 and show that preservatives reduce their size up to one fifth, when grinded for six minutes. The values represent the average of two determinations. Stabilizers (wetting agents and dispersants) were added to the samples to prevent agglomeration of crystals. Although the resulting particle sizes are very close, there seems to be a tendency of increasing the particle size with time, indicating agglomeration of particles (Welin-Berger and Bergenstahl, 2000). This increasing is negligible compared to the magnitude and extent of the uncertainty in its determination, and therefore it was neglected.

The smaller the particle size, the most effective the preservative should be in the microbiological control.
The explanation for this is that with smaller particle sizes, preservatives cover a larger surface area and can be used in lower concentrations. In smaller sizes, these additives also migrate more easily to the surface, becoming more bio-available to control microbes.

\section{UATR ANALYSIS AFTER GRINDING OF PRESERVATIVES}

The UATR paint spectra, with and without preservatives and grinding, compared to UATR reference spectra of the additives (OIT, diuron, and carbendazim), are shown in Fig. 5. The band with low intensity around $3320 \mathrm{~cm}^{-1}$ (N-H group), detected in the spectra of paints containing grinded preservatives (specially the six-minute grinded sample), and the peaks at $1625 \mathrm{~cm}^{-1}(\mathrm{C}=\mathrm{O}$ group and $\mathrm{C}=\mathrm{N}$ 5-membered heterocyclic ring), and around $1330 \mathrm{~cm}^{-1}$ (C-N group), may indicate the presence of carbendazim. The absorption around $1625 \mathrm{~cm}^{-1}$ might have also contributed to the OIT bands around $1620 \mathrm{~cm}^{-1}$ ( $\mathrm{C}=\mathrm{O}$ group). The band around $870 \mathrm{~cm}^{-1}(\mathrm{C}-\mathrm{H}$ aromatic substitution group) might be from the additives diuron and/or carbendazim, and the absorption observed at $782 \mathrm{~cm}^{-1}$ (vibration of five-membered heterocyclic ring), from the additive OIT.

Table 1. Particle sizes of preservatives.

\begin{tabular}{|c|c|c|c|c|c|c|}
\hline \multirow{3}{*}{ Sample } & \multicolumn{6}{|c|}{ Particle size $(\mu \mathrm{m})$} \\
\hline & \multicolumn{2}{|c|}{ Without grinding } & \multicolumn{2}{|c|}{ Grinding for 1 minute } & \multicolumn{2}{|c|}{ Grinding for 6 minutes } \\
\hline & Zero time & 3 months & Zero time & 3 months & Zero time & 3 months \\
\hline 1 & $32.073 \pm 0.422$ & $33.148 \pm 0.234$ & $14.711 \pm 0.102$ & $14.900 \pm 0.101$ & $4.963 \pm 0.023$ & $5.234 \pm 0.036$ \\
\hline 2 & $31.834 \pm 0.357$ & $35.133 \pm 0.289$ & $16.529 \pm 0.115$ & $16.987 \pm 0.078$ & $6.487 \pm 0.109$ & $6.610 \pm 0.101$ \\
\hline 3 & $32.189 \pm 0.309$ & $33.390 \pm 0.415$ & $11.870 \pm 0.111$ & $13.041 \pm 0.099$ & $5.992 \pm 0.197$ & $6.123 \pm 0.099$ \\
\hline 4 & $32.558 \pm 0.178$ & $32.098 \pm 0.238$ & $4.570 \pm 0.098$ & $15.067 \pm 0.121$ & $5.336 \pm 0.136$ & $5.897 \pm 0.020$ \\
\hline 5 & $31.845 \pm 0.310$ & $33.022 \pm 0.102$ & $15.460 \pm 0.201$ & $16.001 \pm 0.309$ & $4.196 \pm 0.099$ & $4.223 \pm 0.021$ \\
\hline 6 & $32.012 \pm 0.284$ & $32.917 \pm 0.287$ & $15.649 \pm 0.193$ & $16.122 \pm 0.235$ & $5.971 \pm 0.099$ & $5.992 \pm 0.113$ \\
\hline
\end{tabular}




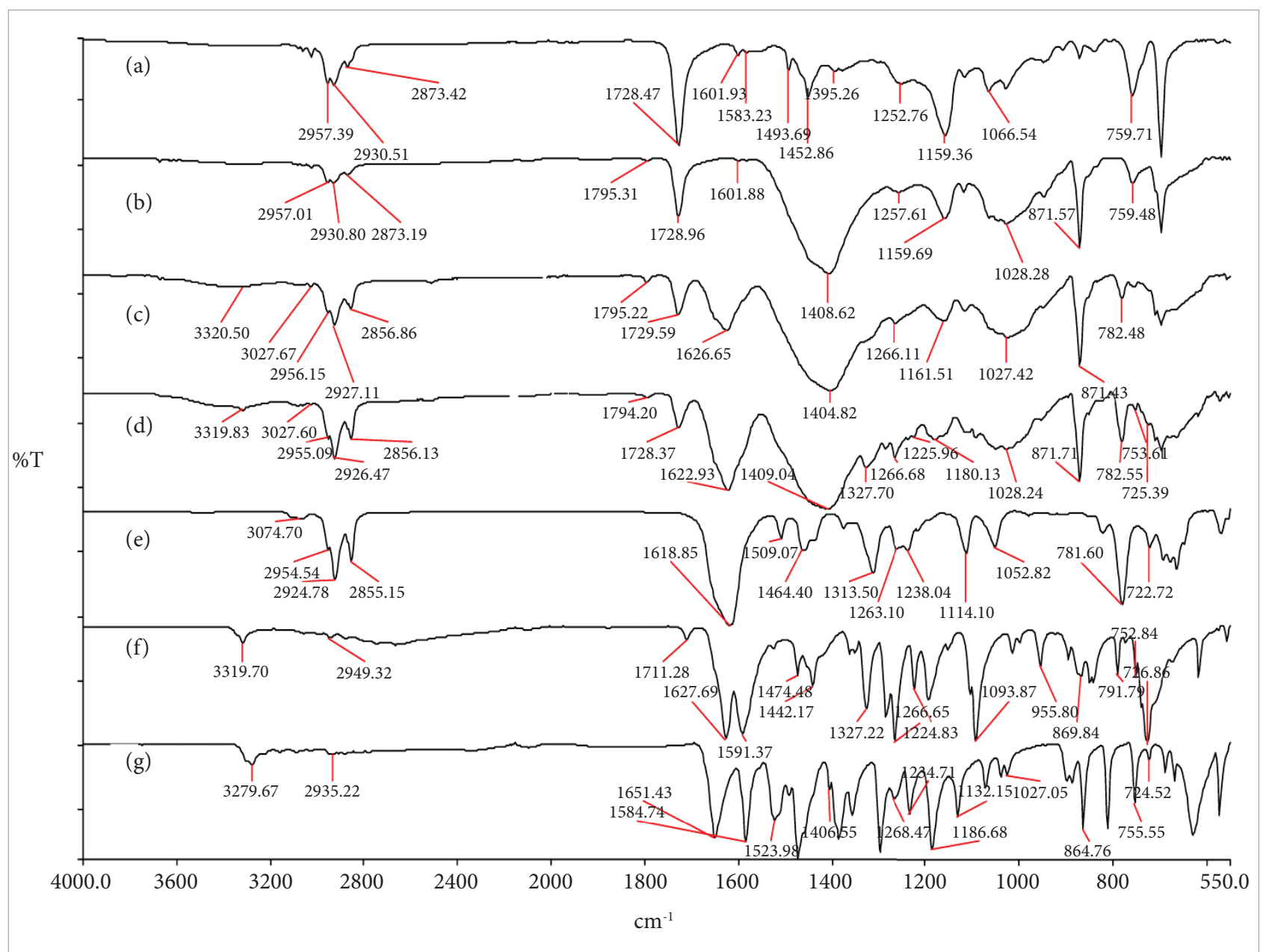

Figure 5. Spectra of UATR - (a) paint without preservatives, (b) paint with preservatives, without grinding, (c) paint with preservatives, grinded during one minute, (d) paint with preservatives, grinded during six minutes, (e) OIT, ( $f$ ) carbendazim, and (g) diuron.

\section{CONCLUSIONS}

The evaluation of IR techniques for the characterization of elastomers and coatings indicated that:

- Transmission and reflection techniques applied to the same rubber sample, NBR in this study, can provide different information, highlighting only the base polymer characteristic absorptions (by pyrolysis/transmission) or the filler ones (by KBr pellet/transmission and ATR or UATR/ reflection). This methodology can be applied to other types of rubber, particularly silicone formulations that might or might not contain silica filler. This aspect can be easily verified by using reflection analysis (ATR or UATR).

- The studied EPDM/NR mixture can be identified only by using the pyrolysis technique and after treatment with ortho-dichlorobenzene. This method is suitable only for mixtures whose characteristic bands do not overlap.

- The UATR technique, without grinding of preservatives, did not allow the direct analysis of the painted dry film, for the samples analyzed. However, after the preservatives had been grinded, it was possible to observe bands around 3300 and $1330 \mathrm{~cm}^{-1}$ (carbendazim), $1625 \mathrm{~cm}^{-1}$ (carbendazim and/or OIT), $870 \mathrm{~cm}^{-1}$ (diuron and/or carbendazim), and $782 \mathrm{~cm}^{-1}$ (OIT).

- By using different FT-IR techniques, the preservatives carbendazim and OIT allow better visualization of the painted surface after grinding, because of their characteristics bands (medium and intense bands of functional groups and/or higher diffusion). 


\section{REFERENCES}

Abidi, N. and Hequet, E., 2005, "Fourier Transform Infrared analysis of trehalulose and sticky cotton yarn defects using ZnSe-Diamond UATR", Textile Research Journal, Vol. 75, No. 9, pp. 645-652.

Allen, T.J., 1992, "Paint sample presentation for Fourier transform infrared microscopy", Vibrational Spectroscopy, Vol. 3, No. 3, pp. 217-237.

Almeida, E., Balmayore, M. and Santos, T., 2002, "Some relevant aspects of the use of FTIR associated techniques in the study of surfaces and coatings", Progress in Organic Coatings, Vol. 44, No. 3, pp. 233-242.

American Society for Testing and Materials - ASTM, 2010, "Book of ASTM Standards", Philadelphia, D 3677-10, Standards Test Methods for Rubber-Identification by Infrared Spectrophotometry.

Blackford, R., 1999, "Performance demands on aerospace paints relative to environmental legislation", Pigment \& Resin Technology, Vol. 28, No. 6, pp. 331-335.

Campos, E.A., Diniz, M.F., Reis, T.B., Dutra, R.C.L., Rezende, L.C. and Iha, K., 2003, "Aplicação de Técnicas FT-IR na Caracterização de Catalisador Cromito de Cobre. Utilizado na Indústria Aeroespacial", Anais Associação Brasileira de Química, Vol. 52, No. 1, pp. 22-25.

Crespim, H., Azevedo, M.F.P, David, L.H., Cassu, S.N. and Lourenço, V.L., 2007, "Substituição de amianto por silicato de alumínio e grafite expansivel em compósito de poliuretano utilizado em motor-foguete", Polímeros: Ciência e Tecnologia, Vol. 17, No. 3, pp. 228-233.

Dutra, J.C.N., Massi, M., Otani, C., Dutra, R.C.L., Diniz, M.F., Urruchi, W.I., Maciel, H. and Bittencourt, E., 2002, "Surface Modification of EPDM Rubber by Reactive Argon-Oxygen Plasma Process", Molecular Crystals and Liquid Crystals, Vol. 374, No. 1, pp. 45-52.

Dutra, R.C.L. and Diniz, M.F., 1993, "Resistência à degradação oxidativa e comportamento aos solventes como indicadores da composição de sistemas elastoméricos vulcanizados mistos", Polímeros: Ciência e Tecnologia, Vol. 3, No. 3, pp. 25-28.

Dutra, R.C.L., Diniz, M.F., Takahashi, M.F.K., 1995, "Importância da Preparação de Amostras em Espectroscopia no Infravermelho com Transformada de Fourier (FTIR) na Investigação de Constituintes em Materiais Compostos", Polímeros: Ciência e Tecnologia, Vol. 5, No. 1, pp. 41-46.

Faillace, J.C., Medeiros, M.E., Filho, A.M.F., 1999, "Comportamento Térmico do Acelerador de Queima de Propelentes Sólidos, Anais do III Encontro Técnico de Materiais e Química, $3^{\text {th }}$ ETMQ, Rio de Janeiro, Brazil.

Ferrari, V.C.G.M., Lourenço, V.L., Dutra, R.C.L., Diniz, M.F., Azevedo, M.F.P., David, L.H., 2012, "Caracterização de um Pré-Impregnado Aeronáutico por FT-IR e Análise Térmica”, Polímeros: Ciência e Tecnologia, Vol. 22, No. 4, pp. 369-377

Hori, K., Iwama, A., Fukuda, T., 1990, "FTIR spectroscopic study on the Interaction between Ammonium Perchlorate and Bonding Agents", Propellants, Explosives, Pyrotechnics, Vol. 15, No. 3, pp. 99-102.

Lindner, W., 2005, "Surface Coatings", In: Directory of Microbicides for the Protection of Materials, Edited by Paulus, W., Springer, New York.
Lourenço, V.L., Kawamoto, A.M., Sciamareli, J., Rezende, L.C., Pires, D.C., Takahashi, M.F.K., Berdugo, A.V., Cruz, S.M., Dutra, R.C.L. and Soares, B.G. 2006, "Determinação da distribuição de funcionalidade de HTPB e verificação de sua influência no comportamento mecânico de poliuretano utilizado em motor-foguete", Polímeros: Ciência e Tecnologia, Vol. 16, No. 1, pp. 66-70.

Mateo, M.P., Ctvrtnickova, T. and Nicolas, G., 2009, "Characterization of pigments used in painting by means of laser-induced plasma and attenuated total reflectance FTIR spectroscopy", Applied Surface Science, Vol. 255, No. 10, pp. 5172-5176.

Matheson, M.J., Wampler, T.P., Simonsick Jr., W.J., 1994, "The effect of carbon-black filling on the pyrolysis behavior of natural and synthetic Rubbers", Journal of Analytical and Applied Pyrolysis, Vol. 29, No. 2, pp. 129-136.

Mattos, E.C., Moreira, E.D., Dutra, R.C.L., Diniz, M.F., Ribeiro, A.P. and Iha, K., 2004, "Determination of the HMX and RDX content in synthesized energetic material by HPLC, FT-MIR and FT-NIR spectroscopies", Química Nova, Vol. 27, No. 4, pp. 540-544.

Mazzeo, R., Joseph, E., Prati, S. and Millemaggi, A., 2007, "Attenuated Total Reflection Fourier Transform Infrared Microspectroscopic Mapping for the Characterization of Paint Cross Sections", Analytica Chimica Acta, Vol. 599, No. 1, pp. 107-117.

Mello, V.M. and Suarez, P.A.Z., "As Formulações de Tintas Expressivas Através da História", Revista Virtual de Química, Vol. 4, No. 1, pp. 2-12, Retrieved on June 11 2013, 2012, from http://www.uff.br/ $\mathrm{RVQ} /$ index.php/rvq/article/viewFile/248/218

Miliani, C., Ombelli, M., Morresi, A. and Romani, A., 2002, "Spectroscopic study of acrylic resins in solid matrices", Surface and Coatings Technology, Vol. 151-152, pp. 276-280.

Moraes, J.H., Sobrinho, A.S.S., Maciel, H.S., Dutra, J.C.N., Massi, M., Mello, S.A.C. and Schreiner, W.H., 2007, "Surface improvement of EPDM rubber by plasma treatment", Journal of Physics D: Applied Physics, Vol. 40, No. 40 pp. 7747. dx.doi.org/10.1088/0022-3727/40/24/022

Oliveira, J.I.S., Nagamachi, M.Y., Diniz, M.F., Mattos, E.C. and Dutra, R. C.L., 2011, "Assessment of the synthesis routes conditions for obtaining ammonium dinitramide by the FT-IR", Journal of Aerospace Technology and Management, Vol. 3, No. 3, pp. 269-278.

Pandey, G.C. and Kulshreshtha, A.K., 1993, "Fourier transform infrared spectroscopy as a quality control tool", Process Control and Quality, Vol. 4, pp. 109-123.

Pardini, L.C., 2000, "Preformas para Compósitos Estruturais", Polímeros: Ciência e Tecnologia, Vol. 10, No. 2, pp. 100-109.

Perkin Elmer - Technical Note, 2005, Improved Performance with the New Spectrum 100 UATR Accessory, Retrieved on June 11 2013, from www. perkinelmer.com

Romão, B.M.V., Diniz, M.F., Azevedo, M.F.P, Lourenço, V.L., Pardini, L.C., Dutra, R.C.L., Burel, F., 2006, "Characterization of the Curing Agents Used in Epoxy Resins with TG/FT-IR Technique", Polímeros: Ciência e Tecnologia, Vol. 16, No 2, pp. 94-98.

Sanches, N.B., Diniz, M.F., Reis, T.B., Cassu, S.N., Dutra, R.C.L., 2006, "Avaliação do uso de técnicas PIR-G/FT-IR para caracterização de Elastômeros", Polímeros: Ciência e Tecnologia, Vol. 16, No. 3, pp. 211-216. 
Santos, R.P., Oliveira Junior, M.S., Mattos, E.C., Diniz, M.F. and Dutra, R.C.L., 2013, "Study by FT-IR Technique and Adhesive Properties of Vulcanized EPDM Modified with Plasma", Journal of Aerospace Technology and Management, Vol. 5, No. 1, pp. 65-74.

Sciamareli, J., Cassu, S.N. and Iha, K., 2012, "Water influence in poly (epichlororydrin) synthesis: An Intermediate to Energetic Propellants", Journal of Aerospace Technology and Management, Vol. 4, No. 1, pp. 41-44. doi:10.5028/jatm.2012.04016011

Silverstein, R.M., Webster, F.X. and Kiemle, D.J., 2005, "Spectrometric identification of organic compounds", John Wiley \& Sons, New York.

Smith, A.L., 1979, "Applied Infrared Spectroscopy", John Wiley \& Sons, New York, pp. 286.

Szafarska, M., Woźniakiewicz, M., Pilch, M., Zięba-Palus, J. and Kościelniak, P., 2009, "Computer analysis of ATR-FTIR spectra of paint samples for forensic purposes. Journal of Molecular Structure", Vols. 924-926, pp. 504-513.
Wake, W.C., Tidd, B.K. and Loadman, M.J.R., 1983, "Analysis of Rubber and Rubber-like polymer", $3^{\text {rd }}$ edition, Applied Science Publishers, New York, pp. 330.

Waltham, 2005, FT-IR Spectroscopy Attenuated Total Reflectance (ATR), Technical Note, Catalogue PerkinElmer.

Welin-Berger, K. and Bergenstahl, B., 2000, "Inhibition of Ostwald ripening in local anesthetic emulsions by using hydrophobic excipients in the disperse phase". International Journal of Pharmaceutics, Vol. 200, No. 4, pp. 249-260.

Williams, P.T. and Besler, S., 1995, "Pyrolysis-thermogravimetric analysis of tires and tyre components", Fuel, Vol. 74, No. 9, pp. 1277-1283.

Zhang, W.R., Lowe, C. and Smith, R., 2009, "Depth profiling of coil coating using step-scan photoacoustic FTIR", Progress in Organic Coatings, Vol. 65, No. 4, pp. 469-476. 